\title{
Automatic System for Detection and Positioning of Impacts in Metals Based on Arduino
}

\author{
Carlos Morón (D), ${ }^{1}$ Daniel Ferrández, ${ }^{2}$ Pablo Saiz, ${ }^{3}$ and Alberto Morón ${ }^{1}$ \\ ${ }^{1}$ Departamento de Tecnologías de la Edificación, Grupo Sensores y Actuadores, Universidad Politécnica de Madrid, \\ Juan de Herrera 6, Madrid 28040, Spain \\ ${ }^{2}$ Departamento de Ingeniería de Organización, Administración de Empresas y Estadística, Grupo Sensores y Actuadores, \\ Universidad Politécnica de Madrid, Madrid 28660, Spain \\ ${ }^{3}$ Universidad Rey Juan Carlos, Departamento de Economía Financiera, Contabilidad e Idioma Moderno, Campus de Vicálvaro, \\ España Paseo de los Artilleros, s/n, 28032 Madrid, Spain
}

Correspondence should be addressed to Carlos Morón; carlos.moron@upm.es

Received 25 February 2019; Accepted 7 May 2019; Published 28 May 2019

Academic Editor: Franck Poisson

Copyright (C) 2019 Carlos Morón et al. This is an open access article distributed under the Creative Commons Attribution License, which permits unrestricted use, distribution, and reproduction in any medium, provided the original work is properly cited.

This work presents a new application to detect vibrations in metallic structures based on low-cost sensors compatible with the Arduino platform that enables identification of points where the impact is produced, in order to facilitate inspection. If the impact is produced on a metal bar, the energy introduced in the system is spread through the material in the form of vibration. Thus, using standardized construction steel rods B500SD that can be considered homogeneous along entire section, it was possible to detect where the impact is produced, measuring delays of propagation of acoustic wave throughout the material. For that, it was necessary to place the accelerometers at the ends of the structure that enables an automatic and efficient way to determine the moment and the position of the impact. Hypothesis of supported beam was taken into consideration, obtaining for distances of 0.1 and $0.9 \mathrm{~m}$ with delay times of $500 \mu \mathrm{s}$.

\section{Introduction}

At present, there is a great variety of tests and measurement equipment destined to study the transmission of vibrations through different construction materials $[1,2]$. The impacts produced on the surface of any construction element generate an acoustic component named impact noise which means a vibration that can be perceived even at the great distance from the emitting source [3]. In any case, airborne noise introduced by a vibration can be detected by the human ear from the frequencies of $16 \mathrm{~Hz}$ [4].

Inspection techniques are crucial to improve the security and reliability of the structures, especially those that require a process of rehabilitation due to their age and those that are under constant use requests $[5,6]$. A particular type of inspection is the one that is required when a nonprogrammed event happens in the structure, as in the case of an impact that has to be examined.
There are different techniques of measuring vibrations produced by an impact; some of them are focused on quantification of vibration without determining the position where collision occurs. Such is the case of inspection with ultrasounds [7], the test of damaged structure through $\mathrm{X}$ rays [8], or the search of resonance frequency of material for the case of continuous pulsations induced on the structure and that can cause its collapse [9]. Some authors progressed in this area, developing new measuring equipment to detect impact vibrations based on capacitive sensors connected to selfoscillating circuits [10], in deformation produced in the structure starting vibration, using for these extensiometric gauges [11] or in variations produced in emanation of metallic material under a pulling tension [12]. Other researches have focused not so much on the quantification of the impact but on determining its position, using infrared thermography or [13] or using sensors able to determine the delay produced in the wave until reaching its position to extrapolate 
subsequently location of impact. The use of piezoelectric devices stands out among these sensors [14]. All these systems developed for impacts detection are expensive in their majority, and that is why it is practical to develop cheap measuring systems of the same quality, in order to obtain similar results being used in the construction sector.

On the other hand, metal structures are very commonly used in the building sector. The great majority of skyscrapers built in the USA have metal structure, and it is estimated that there are more than 42000 metal bridges in the EU [15]. These metal structures can be bolted or welded, and they can be considered as jointed or integrated, depending on the behaviour of the beam towards external impact [16]. Inspection tasks are usually monitored and performed by the programmed robots being able to accede to any point of the structure without the necessity of human intervention. It is necessary to indicate to the robot exact destination data that enable to plan the route of navigation in order to find the interest zone where the impact was produced [17]. The main disadvantage is that these commercial robots do not have a free programming code and their functions are predetermined by the manufacturer. In this way, any try to use microcontrollers based on free software allows engineers to modify inspection equipment and adapt it to different situations according to the kind of structure, technician abilities, etc.

In the past decades, various systems of impact detection have been developed. In general, they are used in structures under risk such as nuclear plants or in canalizations of fluids with risk of leakage. For this, methods able to measure with precision the delay in arrival times between two connected sensors were used [18], in the analysis of responses of tension and deformation in structures in order to establish relation between them that would enable to calibrate the magnitude of the impact [19] or in the propagation of impact noise through the material adjusting to the model of vibration of a tight membrane [20] or of an infinite linear solid [21]. Moreover, all of them are generally expensive methods and are difficult to implement without adequate equipment.

This work presents a new measuring system based on the use of low-cost accelerometers compatible with the Arduino platform with the consequent advantage of being a free software and compatible with other programs of commercial use. The devise enables automatic measuring that facilitates detection and positioning of impacts on metal structures, especially recommended for linear elements such as steel beams. Using this type of systems robotic inspection tasks can be improved in the impact zone, avoiding, to the extent possible, human risk derived from direct visual inspections.

\section{Experimental Process}

2.1. Velocity of Wave Propagation in Steel Beams. In the case of steel beam of transversal uniform section, which is under the impact in a way that the wave length of produced vibration is bigger to the thickness of the transversal differential element chosen, this perturbation spreads throughout the beam in a way that the deformation produced at longitudinal direction does not depend on traction of transversal compression force. This model can be adjusted to the propagation of elastic waves in a fine solid bar.

To define this model, it is necessary to use the unitary deformation in the $x$ direction (longitudinal of the bar), that is given by the following expression:

$$
\varepsilon=\frac{\partial l}{\partial x}
$$

and elastic tension is defined by

$$
\sigma=\frac{\mathscr{F}}{S}
$$

where $\mathscr{F}$ is a set of forces that act through one section of the bar and $S$ is the section of the bar.

Moreover, for the one-dimensional state of tension with small deformations, both expressions are related by Hooke's Law:

$$
\sigma=E \varepsilon
$$

where $E$ is Young's modulus of steel.

One differential section of the bar of $d x$ thickness placed on $x$ moves to $x^{\prime}=x+l$ during the passage of the wave, and its thickness becomes $d x^{\prime}=d x+d l$ (Figure 1). When the perturbation is in propagation, elastic tension $\sigma(x)$ over each section is not the same and that is why one thickness area $d x$ is under net force:

$$
F^{\prime}-F=d F=A \frac{\partial \sigma}{\partial x} d x=\frac{\partial \mathscr{F}}{\partial x} d x,
$$

to the right, taking as positive direction of the tractions over each surface differential. And given that the mass of each section is $d m=\rho A d x$, where $\rho$ is the density of steel, the equation of movement in surface differential is

$$
d F=a d m \Rightarrow A \frac{\partial \sigma}{\partial x} d x=\rho A d x \frac{\partial^{2} l}{\partial t^{2}} \Rightarrow \frac{\partial \sigma}{\partial x}=\rho \frac{\partial^{2} l}{\partial t^{2}} .
$$

Replacing in the previous expression with the obtained relation of Hooke's Law, the following expression is obtained:

$$
\frac{\partial^{2} l}{\partial t^{2}}=\frac{E}{\rho} \cdot \frac{\partial^{2} l}{\partial x^{2}}=c^{2} \frac{\partial^{2} l}{\partial x^{2}}
$$

The expression similar to the equation of waves indicates that the displacement field is spread throughout the steel bar with the following speed:

$$
c=\sqrt{\frac{E}{\rho}}
$$

Thus, an impact on a metal bar produces a deformation in the form of flexion that moves the material from the surrounding areas. Moreover, steel particles involved in the movement do it only in the infinitesimal area around the equilibrium position, due to the restoring elastic forces of the material. In this way, the only progressive energy is one of the impacts that manifest itself in the form of vibration moving at a proper speed of each material, and that is $5900 \mathrm{~m} / \mathrm{s}$ in the case of studied steel. 


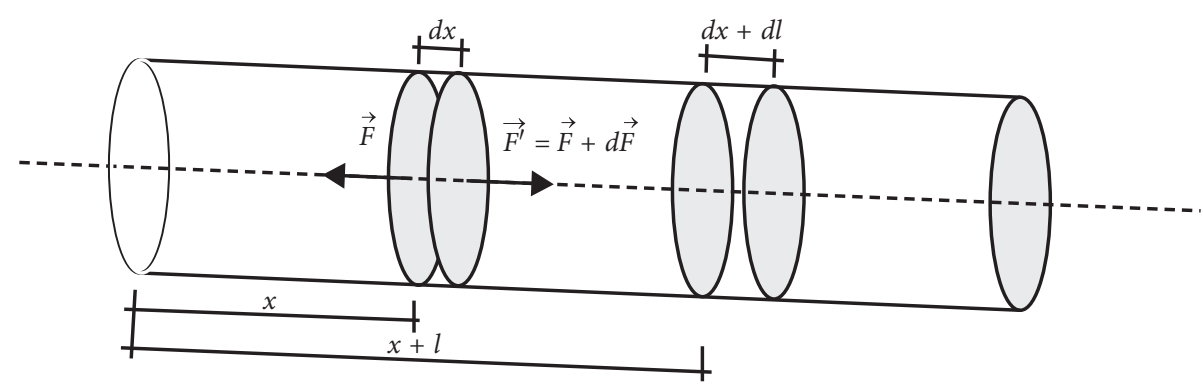

Figure 1: Propagation of vibration along a steel bar.

Two corrugated steel bars of 0.5 and $1 \mathrm{~m}$ length were used in this work. According to Spanish Instruction on Structural Concrete (EHE-08) [22], the used steel is of class B500SD, which is a hot rolled steel with a guaranteed elastic limit of $500 \mathrm{MPa}$, weldable, and with a special plasticity, recommended for structures subjected to seismic activity. This is a steel with a total lengthening under a maximum load $\varepsilon_{\max }=12 \%$, able to withstand more than two million of cycles without braking under fatigue tests. Among all the available diameters, diameter of $0.016 \mathrm{~m}$ has been chosen, as it is the most commonly used in the building diameter, due to its ease of use and good weight performance [23].

2.2. Model for Detection of Impact in Steel Bars. The steel bar can be considered as a simple structure according to its supports (Figure 2), allowing the bar to deflect freely without the supports mitigating the vibration. In this manner, when a falling mass hits the surface of the bar with a certain energy, this energy spreads as an impact noise through the material until reaching the ends of the bar.

Steel is not an acoustic insulation material, and for this reason, the energy dissipated in the form of heat can be considered negligible for short distances. Moreover, as this is a standardized construction steel B500SD, it can be considered to be homogeneous throughout the whole surface in a way that the time the wave takes to reach the ends of the bar will be proportional to the distance at which the impact is produced.

If two accelerometers are placed at the ends of the bar as seen in Figure 2, vibration propagation times will be calculated using the following equations:

$$
\begin{aligned}
& t_{1}=\frac{x}{c_{\mathrm{s}}}, \\
& t_{2}=\frac{L-x}{c_{\mathrm{s}}},
\end{aligned}
$$

where $t_{1}$ and $t_{2}$ are the times taken by the wave to reach the accelerometers 1 and 2, respectively, $x$ is the distance between the point where the impact is produced and the accelerometer $1, L$ is the length of the bar, and $c_{\mathrm{s}}$ is the speed of acoustic propagation through the steel.

The difference between the times $t_{1}$ and $t_{2}$ can be calculated directly as the difference between the two previous times, as defined by the following expressions:

$$
\begin{aligned}
& \Delta t_{12}=t_{2}-t_{1}=\frac{L-2 x}{c_{s}}, \\
& \Delta t_{21}=t_{1}-t_{2}=\frac{2 x-L}{c_{s}} .
\end{aligned}
$$

Concluding from the previous expressions, the position of the impact can be determined if the length $L$ of the bar and the propagation speed in steel $c_{\mathrm{s}}$ are known:

$$
\begin{aligned}
x & =\frac{L-\Delta t_{12} c_{\mathrm{s}}}{2}, \\
\text { or } x & =\frac{L+\Delta t_{21} c_{\mathrm{s}}}{2} .
\end{aligned}
$$

Thus, there are three possibilities depending on the position of the impact regarding the center of the bar:

$$
\begin{aligned}
& \text { Case } 1 \begin{cases}\Delta t_{12}>0, & \text { if } x<\frac{L}{2}, \\
\Delta t_{12}=0, & \text { if } x=\frac{L}{2}, \\
\Delta t_{12}<0, & \text { if } x>\frac{L}{2},\end{cases} \\
& \text { or Case } 2 \begin{cases}\Delta t_{21}>0, & \text { if } L-x<\frac{L}{2}, \\
\Delta t_{21}=0, & \text { if } L-x=\frac{L}{2}, \\
\Delta t_{21}<0, & \text { if } L-x>\frac{L}{2} .\end{cases}
\end{aligned}
$$

Furthermore, the initial impact time is obtained directly from the measurement of the first sensor that detects vibration [24].

\subsection{Equipment Designed for Localization and Detection of} Impacts. The method used to determine the moment and the position of the impact is based on the use of accelerometers placed at the ends of the bar, that detect as soon as possible the vibration generated by the impact.

The flow diagram shown in Figure 3 represents the essence of the programming algorithm used to localize the 


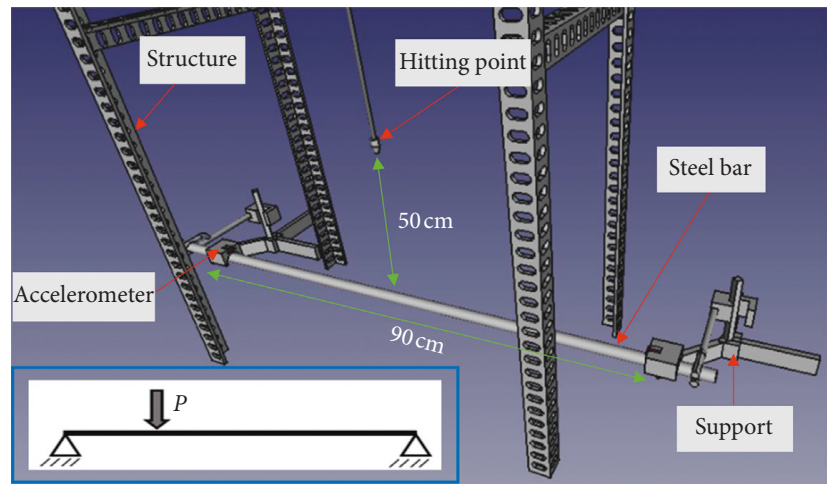

Figure 2: Design in FreeCAD 3D of the hitting equipment and the scheme of the hypothesis.

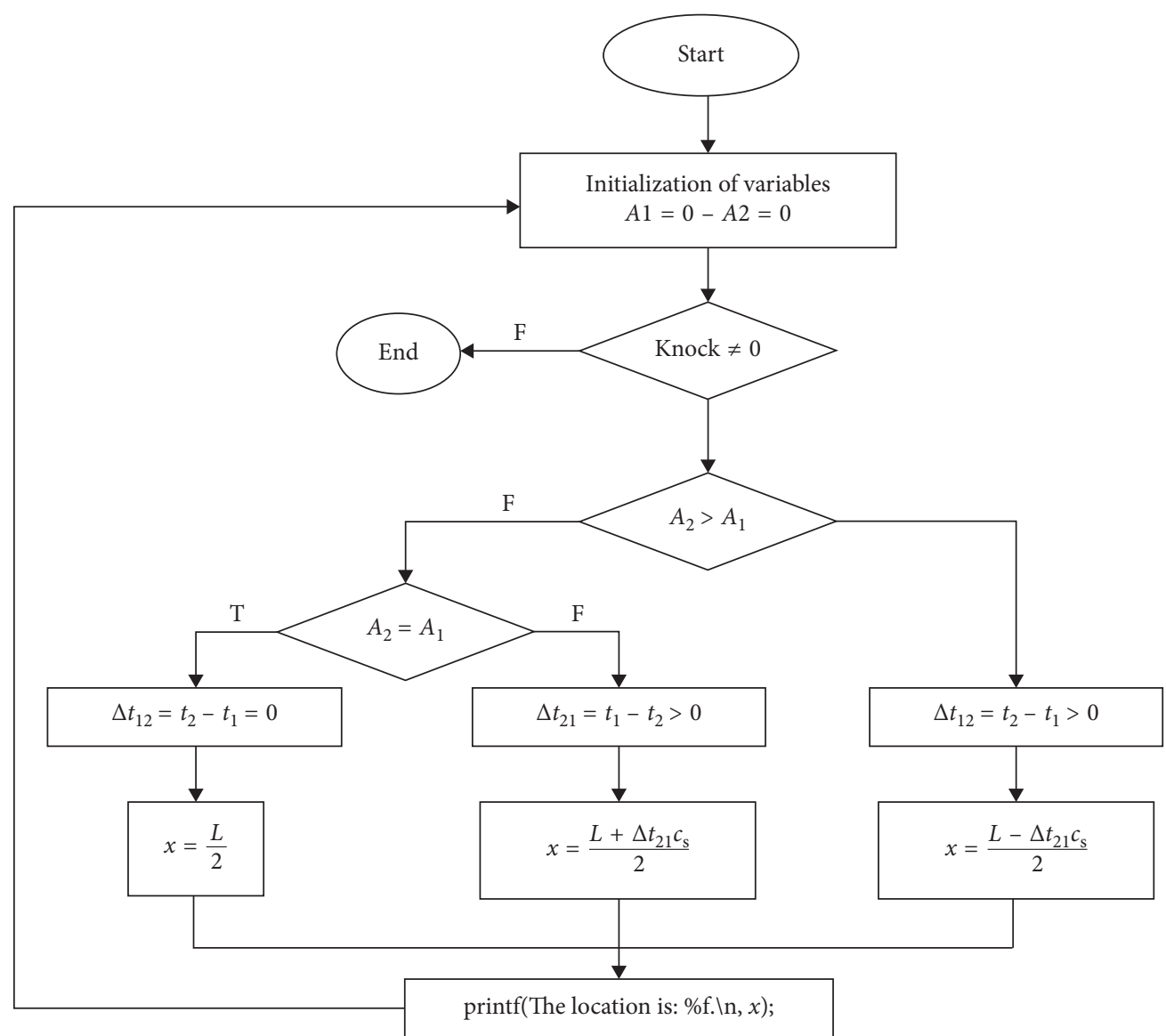

Figure 3: Flow diagram of the implemented program.

impact. The hardware Arduino platform has been chosen due to its advantage of being an open code. Moreover, the set of ins and outs easily assembled in physical format facilitates the prototype installation, and the project can be run without the necessity to be connected to a computer, simply using power battery of $5 \mathrm{~V}$ and adding SD card in order to obtain a major data acquisition.

Figure 4 shows the scheme of measuring equipment with a connection to the accelerometers to the board. The Arduino UNO electronic board based on ATmega328P has been implemented, as it has six analog inputs sufficient for three measuring axes of each accelerometer. The accelerometers are of the series ADXL335 of Arduino, of reduced size and consumption and of high measure accuracy. Additionally, it has a wide range of operation temperatures from $-40^{\circ} \mathrm{C}$ to $85^{\circ} \mathrm{C}$ what makes it optimum for the use in exterior ambient conditions.

\section{Results and Discussion}

3.1. Actual Assembly of the Equipment. Final state of equipment designed for a data collection is shown in 


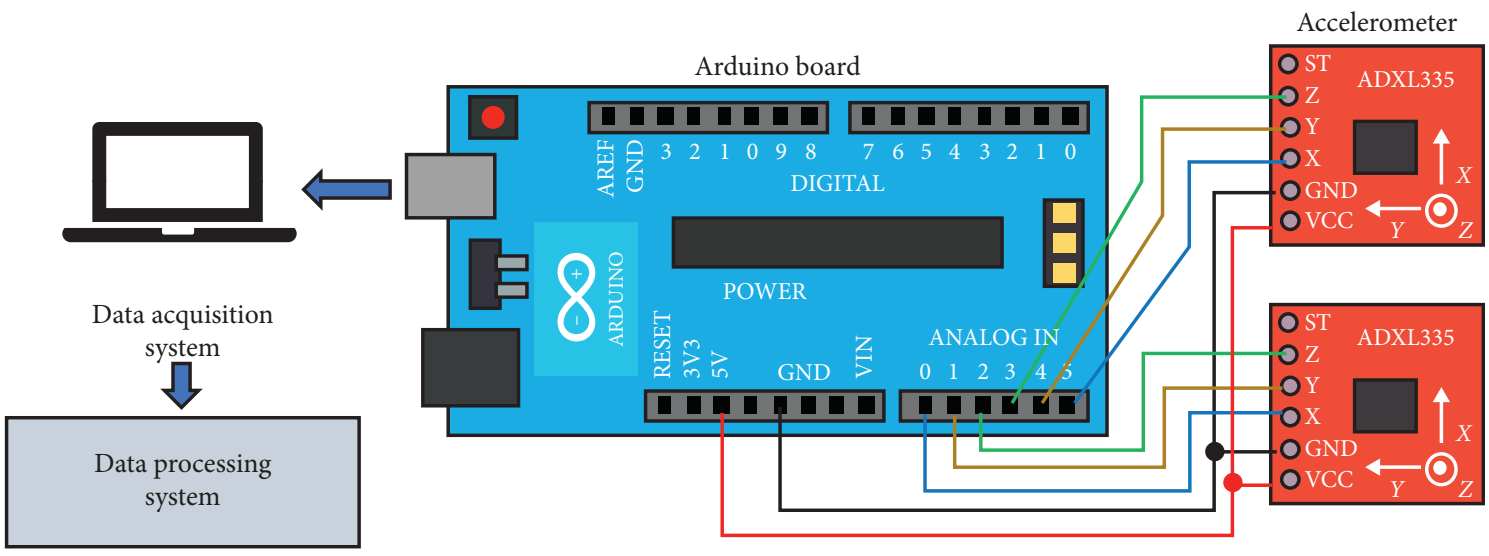

Figure 4: Scheme of measuring equipment with accelerometers.

Figure 5, where each one of the components of the system is included.

3.2. Detection and Location of Impacts. Figures 6 and 7 show delay time obtained from the measurements of two sensors for different positions of hitting in bars of 0.5 and $1 \mathrm{~m}$, respectively. The distances of the hitting were each $0.05 \mathrm{~m}$ in both cases starting from the left support of the bar, with $2.5 \mathrm{~kg}$ mass falling height of $0.5 \mathrm{~m}$ in all the properly calibrated impacts.

As it can be observed in Figures 6 and 7, the relation between time delay between both sensors and the impact position keeps the linear relation in accordance with the theoretical predictions. Furthermore, the correlation coefficient is slightly lower for the bar of $0.5 \mathrm{~m}$; when the distance from the hitting point to the sensor is bigger, it differs more from the range of measuring embraced by the accelerometer. Thus, the distances of one meter are optimum to place the sensors. However, this distance can be amplified if the impact intensity is sufficient so it is not absorbed throughout the bar and reaches with sufficient amplitude in order to be detected by the measuring device. Theoretical predictions for each bar have been included in the graphics.

Once the functioning of the Arduino system is checked for simply supported bars, the use of this method can be extrapolated to the impacts detection in more generic $3 \mathrm{D}$ structures.

General 3D structure is under consideration. If $n$ accelerometers are placed along the structure and acoustic wave uses the shortest way between two sensors, it is possible to perform a model of the structure to place the sensors and to consider $D$ matrix of minimum distances between the sensors:

$$
D=\left(\begin{array}{cccc}
d_{11} & d_{12} & \cdots & d_{1 n} \\
d_{21} & d_{22} & \cdots & d_{2 n} \\
\vdots & \vdots & \ddots & \vdots \\
d_{n 1} & d_{n 2} & \cdots & d_{n n}
\end{array}\right)
$$

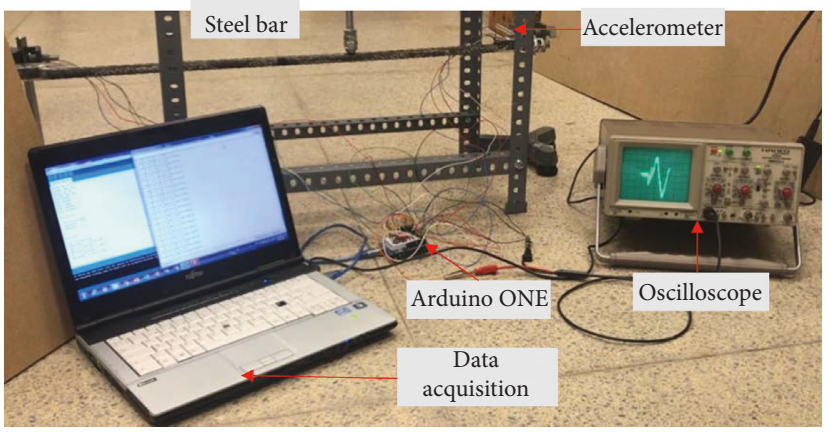

Figure 5: Data collection equipment.

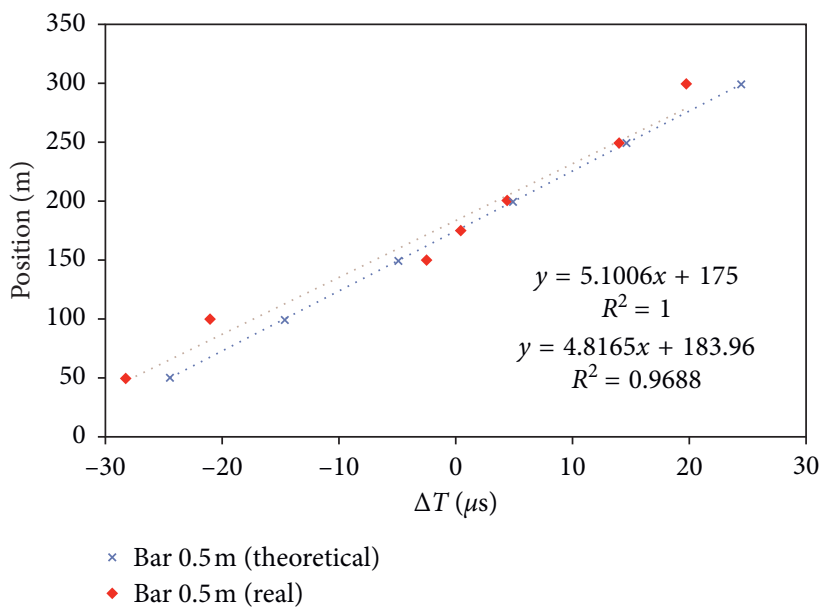

FIgURe 6: Time delay for different impacts; steel bar of $0.5 \mathrm{~m}$.

where $d_{i j}$ minimum distances between the sensors $S_{i}$ and $S_{j}$. As $D$ matrix is symmetric $d_{i j}=d_{j i}, \forall 1 \leq i, j \leq n$ with $i \neq j$, and $d_{i i}=0, \forall 1 \leq i \leq n$.

When there is an impact in the structure, acoustic waves reach each sensor in a way that the times of detection would be

$$
T=\left(\begin{array}{llll}
t_{1} & t_{2} & \cdots & t_{n}
\end{array}\right),
$$




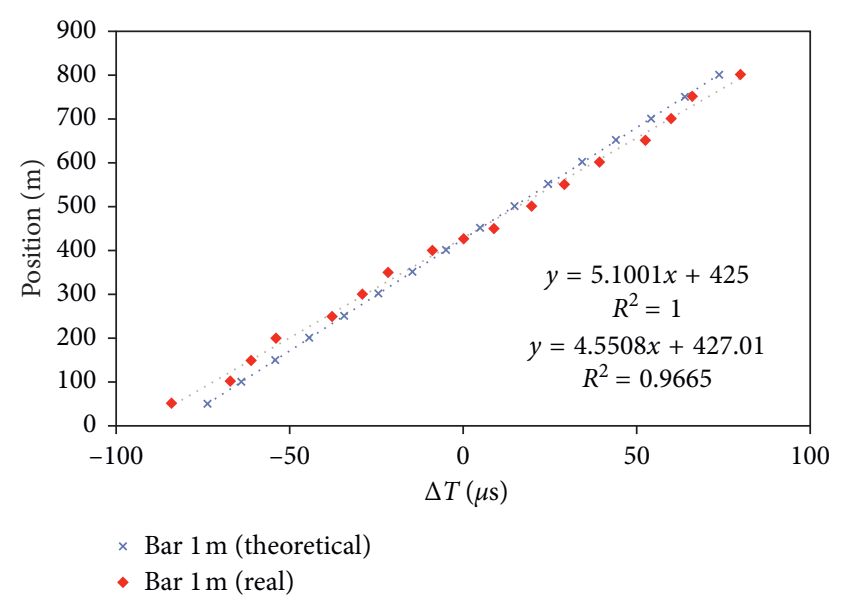

Figure 7: Time delay for different impacts; steel bar of $1 \mathrm{~m}$.

where $t_{i}, \forall 1 \leq i \leq n$, is the propagation time from the point of impact to the accelerometer $S_{i}$.

As in the simplest case of only one bar, these times cannot measured directly, and only the differences between the times can be obtained. If sensor $S_{i}$ is the first one in detecting the wave, differences between times from this $i$ th sensor are obtained. Thus, the previous equation is changed to

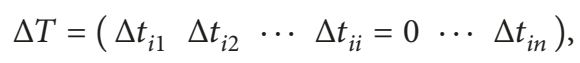

where $\Delta t_{i\left(j_{-} s\right)}, \forall 2 \leq j_{-} s \leq n$ means the propagation time differences between the accelerometers $S_{i}$ and $S_{\left(j_{-} s\right)}$ instead of absolute times. The distances between the accelerometers $S_{i}$ and $S_{\left(j_{s}\right)}$ form the $i$-th row of $D$ matrix, symbolized as $D_{i}$, meaning

$$
D_{i}=\left(\begin{array}{lllllll}
d_{i 1} & \cdots & d_{i(i-1)} & 0 & d_{i(i+1)} & \cdots & d_{\text {in }}
\end{array}\right) .
$$

A similar calculation can be used to obtain relative position $x_{i\left(j_{-} s\right)}$ with respect to $S_{i}$ and can be measured along the way between $S_{i}$ and $S_{\left(j_{-} s\right)}$. It can be clearly observed that the following equation is a generalization of one obtained in the case of only one bar for any pair of sensors:

$$
x_{i\left(j_{-} s\right)}=\frac{d_{i\left(j_{-} s\right)}-\Delta t_{i\left(j_{s}\right)} \cdot c_{m}}{2} .
$$

For each $j, \forall 2 \leq j \leq n$, this last equation has $n-1$ possible solutions, and using them, it is possible to determine the position of the impact [25].

\section{Conclusions}

This work presents a new automatic system for impacts detection based on low-cost sensors, able to detect impacts in metal structures and that can be easily integrated into the robotic inspection systems with an aim to locate collisions in larger structures.

For measuring time delay in vibration propagation caused by the impact over the B500SD steel bar, the implemented system based on the low-cost Arduino platform determines the moment and position of the impact through the algorithm used for ADXL335 accelerometers, obtaining differences in the delay time of $500 \mu \mathrm{s}$ for differences in the impact positions of 0.1 and $0.9 \mathrm{~m}$. Thus, this is a precise system of a high response, with an advantage of being free software that can be easily amplified using other electronic boards as Arduino MEGA that enable measuring more complex structures.

\section{Data Availability}

The data used to support the findings of this study are available from the corresponding author upon request.

\section{Conflicts of Interest}

The authors declare no conflicts of interest.

\section{Authors' Contributions}

All the authors worked in an equitable way during the project. Daniel Ferrández created and designed the tests, Daniel Ferrández analyzed the data, Alberto Morón and Carlos Morón conducted the tests, Daniel Ferrández and Alberto Morón wrote the paper, and Pablo Saiz and Carlos Morón translated and reviewed the final manuscript.

\section{Acknowledgments}

The authors would like to thank the student Ignacio Enríquez for his collaboration, whose help was crucial for taking measurements.

\section{References}

[1] C. Morón, A. García, D. Ferrández, and V. Blanco, "Transmission of impact vibration on concrete and mortar sheets," Shock and Vibration, vol. 2015, Article ID 184648, 6 pages, 2015.

[2] N. D. Boffa, E. Monaco, L. Maio et al., "Hybrid guided wave based SHM system for composite structures for impact and delamination detection combining fiber Bragg grating sensing and piezoelectric patches," in Proceedings of the Health Monitoring of Structural and Biological Systems XII, 106000D, SPIE, Denver, CO, USA, March 2018.

[3] G. Pinte, R. Boonen, W. Desmet, and P. Sas, "Active structural acoustic control of repetitive impact noise," Journal of Sound and Vibration, vol. 319, no. 3-5, pp. 768-794, 2009.

[4] S. Hee Parl and P. Jik Lee, "Effects of floor impact noise on psychophysiological responses," Building and Environment, vol. 116, pp. 173-181, 2017.

[5] A. García, V. Feliu, and J. A. Somolinos, "Gauge based collision detection mechanism for a new three degree of freedom flexible robot," in Proceedings of the 2001 (ICRA) IEEE International Conference on Robotics and Automation, pp. 3853-3858, Seoul, Republic of Korea, May 2001.

[6] B. Sutter, A. Lelevé, M. T. Pham et al., "A semi-autonomous mobile robot for bridge inspection," Automation in Construction, vol. 91, pp. 111-119, 2018.

[7] M. R. Polimeno, I. Roselli, V. A. M. Luprano, M. Mongelli, A. Tatì, and G. de Canio, "A non-destructive testing methodology for damage assessment of reinforced concrete buildings after seismic events," Engineering Structures, vol. 163, pp. 122-136, 2018. 
[8] T. Honda, "Non-destructive inspections for the aging degradation of machinery and structures," Journal of Reliability Engineering Association of Japan, vol. 29, pp. 350-357, 2007.

[9] K. Lee, S.-H. Lee, G.-C. Kim, and S.-S. Woo, "Global vertical resonance phenomenon between steel building and human rhythmic excitations," Journal of Constructional Steel Research, vol. 92, pp. 164-174, 2014.

[10] C. Moron, A. Garcia, and D. Ferrandez, "New system for measuring impact vibration on floor decking sheets," Sensors, vol. 15, no. 1, pp. 635-641, 2015.

[11] Z. Zembaty, P. Bobra, P. A. Bońkowski, S. Kokot, and J. Kuś, "Strain sensing of beams in flexural vibrations using rotation rate sensors," Sensors and Actuators A: Physical, vol. 269, pp. 322-330, 2018.

[12] S. Gontarz and R. Guminski, "New approach to the evaluation of the effort state of steel based on magneto-mechanical effects," Mechanics Research Communications, vol. 82, pp. 14-20, 2017.

[13] T. Hajzargarbashi, H. Nakatani, T. Kundu, and N. Takeda, "Detecting the point of impact on a cylindrical plate by the acoustic emission technique," in Proceedings of the Sensors and Smart Structures Technologies for Civil, Mechanical, and Aerospace Systems; 79810U, SPIE 7981, San Diego, CA, USA, April 2011.

[14] J. A. B. Gripp and D. A. Rade, "Vibration and noise control using shunted piezoelectric transducers: a review," Mechanical Systems and Signal Processing, vol. 112, pp. 359-383, 2018.

[15] C. Morón, M. Portilla, J. Somolinos, and R. Morales, "Lowcost impact detection and location for automated inspections of 3D metallic based structures," Sensors, vol. 15, no. 6, pp. 12651-12667, 2015.

[16] P. Urbán, Construction of Metal Structures, University Club, Civil Engineering, San Francisco, California, USA, 2015, ISBN 9788416479221.

[17] C. León, "Electronic system for detection and location of impacts," Master's thesis, Universidad de Castilla la Mancha, Ciudad Real, Spain, 2003, in Spain.

[18] C. Wu, G. Wen, X. Wu, W. Wang, L. Han, and F. Zhang, "Using an acoustic sensor and accelerometer to measure the downhole impact frequency of a hydraulic impactor," Journal of Natural Gas Science and Engineering, vol. 27, no. 3, pp. 1926-1303, 2015.

[19] C. Morón, A. García, and D. Ferrández, "Learning process of the vibration generation by impact om floor used in building engineering students," in Proceedings of the 9th International Technology, Education and Development Conference (INTED2015), Madrid, Spain, March 2015.

[20] D. Li, Z. Zheng, Y. Tian, J. Y. Sun, X. T. He, and Y. Lu, "Stochastic nonlinear vibration and reliability of orthotropic membrane structure under impact load," Thin-Walled Structures, vol. 119, pp. 247-255, 2017.

[21] J. A. Somolinos, O. D. Cortázar, and V. Feliú, "Impact detection system in a flexible bar," in Proceedings of the XXIV Jornadas de Automática, León, Spain, September 2003.

[22] M. de Fomento, Structural Concrete Instruction, EHE-08/ Permanent Commission of the Concrete, Madrid, Spain, 2010.

[23] J. Calavera, E. González Valle, and J. Fernández, A Summary of the Research Carried Out at INTEMAC on Reinforced Concrete Reinforcements. Notebooks, INTEMAC 22, Madrid, Spain, 1996.

[24] J. A. Somolinos, R. Morales, A. Garcia, and C. Moron, "Piezoelectric sensors system for impact detecting," Sensor Letters, vol. 11, no. 1, pp. 128-130, 2013.

[25] J. A. Somolinos, R. Morales, A. García, and C. Morón, "Amorphous piezoresistive and piezoelectric sensors for robotics applications," Physica Status Solidi (C), vol. 8, no. 11-12, pp. 3175-3178, 2011. 


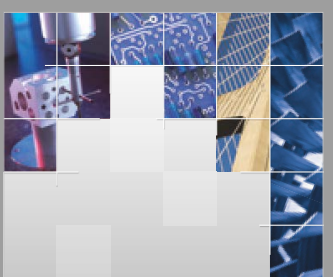

\section{Enfincering}
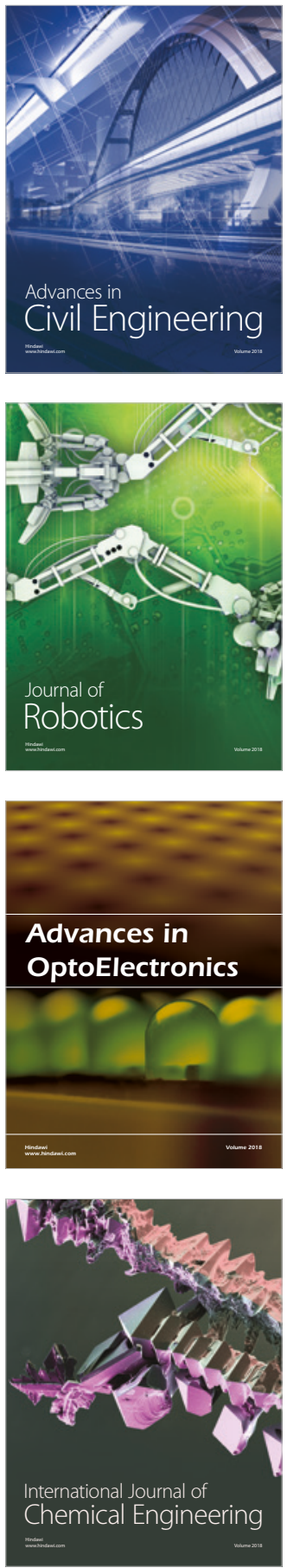

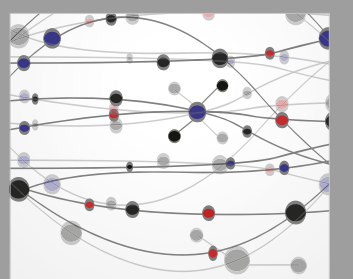

\section{Rotating \\ Machinery}

The Scientific World Journal

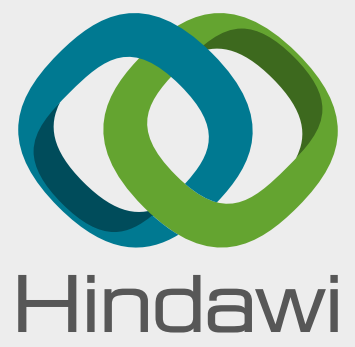

Submit your manuscripts at

www.hindawi.com
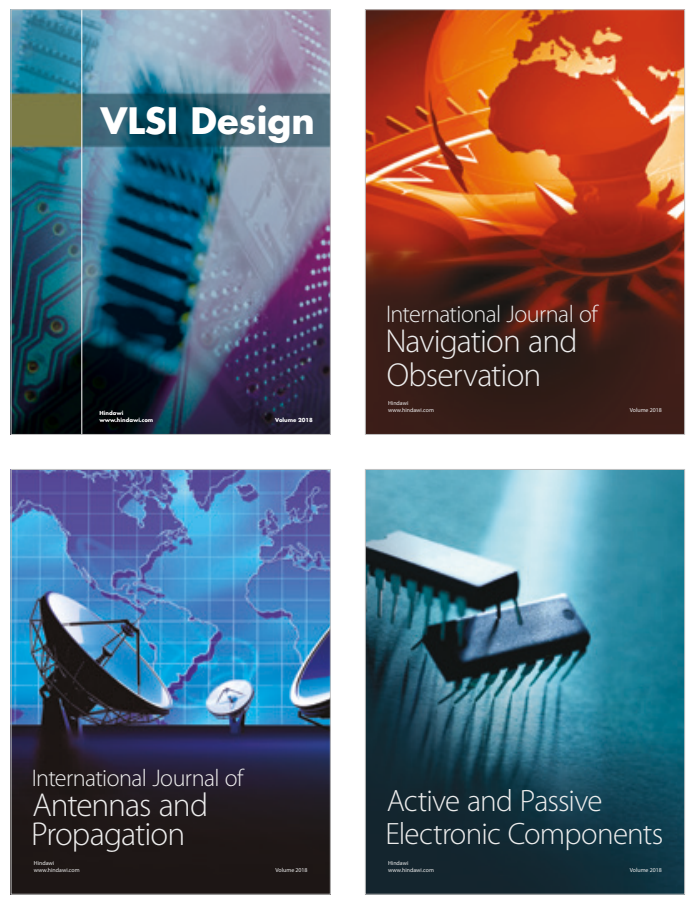
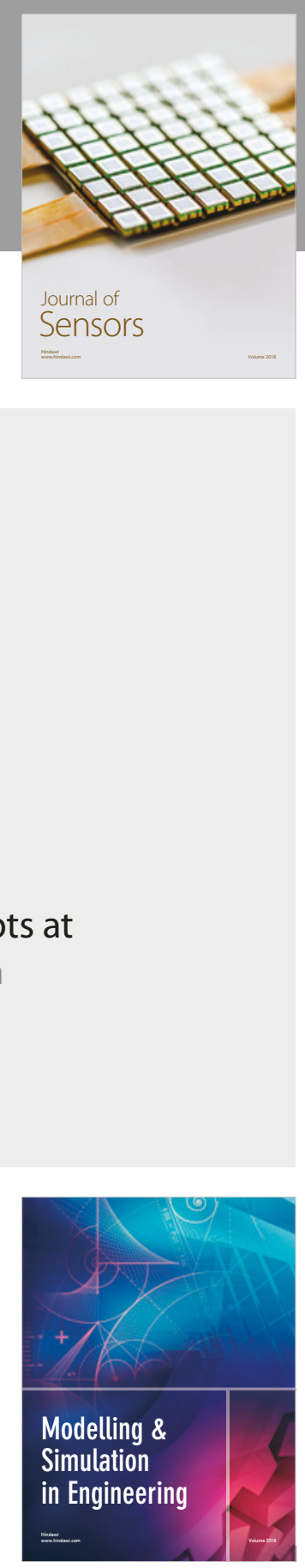

\section{Advances \\ Multimedia}
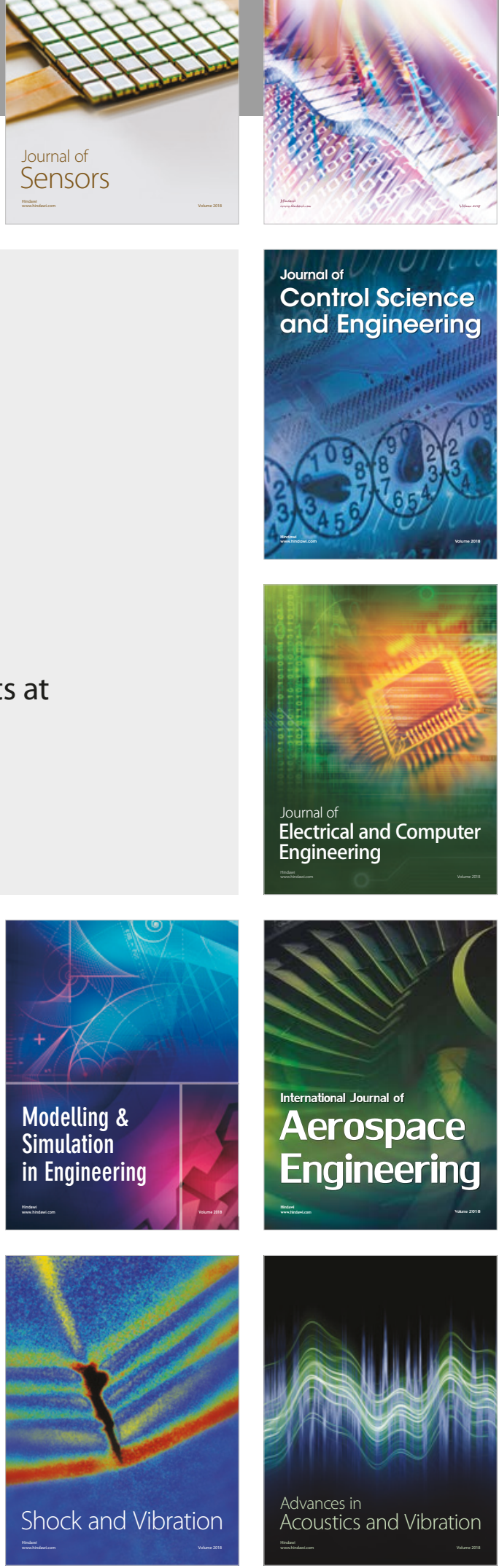